\title{
Development and Investigation of Dry Powder Inhalers for Cystic Fibrosis
}

\author{
Paola Russo, Antonietta Santoro, Lucia Prota, \\ Mariateresa Stigliani and Rita P. Aquino
}

Additional information is available at the end of the chapter

http://dx.doi.org/10.5772/51408

\section{Introduction}

Cystic Fibrosis (CF) is the most common lethal monogenic disorder in Caucasians, estimated to affect one per 2500-4000 newborns. CF is caused by mutations in the gene encoding the CF transmembrane conductance regulator (CFTR) [1, 2]. CFTR acts mainly as a chloride channel and has other regulatory roles, including inhibition of sodium transport through the epithelial sodium channel, regulation of ATP channels and intracellular vesicle transport, acidification of intracellular organelles and inhibition of endogenous calcium- activated chloride channels [3-5]. CFTR is also involved in bicarbonate-chloride exchange [6]. In the airways, loss of functional CFTR promotes increase of oxidation status, tissue injury, modification of intracellular signaling pathways, cell apoptosis and inflammatory processes.

Clinically, the reduced volume of the epithelial lining fluid and the increased viscoelasticity of the mucus lead to a dysfunction of the mucociliary clearance, and as a consequence, patients suffer from recurrent and chronic infections caused mainly by bacteria such as Staphylococcus aureus, Haemophilus influenzae, Burkholderia cepacia, and especially Pseudomonas aeruginosa. Moreover, the chronic $P$. aeruginosa lung infection causes a sustained inflammatory response in the lung. Antibiotics are administered to CF patients in long-term treatment with the hope of maintaining quality of life, weight and lung function, as well as to decrease the number of exacerbations and hospital admission $[7,8]$.

Today there are few formulations, mostly solutions, approved for inhalation in CF patients and there is a continuous research in the development of new inhaled antibiotic therapeutic systems for management of chronic CF lung disease. New formulations and delivery devices are needed to improve efficiency, portability and possibly increase the dose locally available. 
Besides chronic bacterial infections, chronic airway inflammation is uniformly observed in patients with CF $[9,10]$, as a consequence of over-expression of proinflammatory enzymes. Thus, the lung, dipped in an environment rich in oxygen as well as a defective antioxidant system, is susceptible to injury mediated by oxidative stress. Reactive oxygen species, ROS, such as super oxide anion $\left(\mathrm{O}^{2^{*}}\right)$ and hydroxyl radical $\left(\mathrm{OH}^{*}\right)$, and reactive nitrogen species, RNS, such as nitrogen dioxide and peroxynitrite, are unstable molecules with unpaired electrons, capable of initiating oxidation. In order to prevent tissue damage, lungs are endowed with several antioxidant defences, including glutathione, heme oxygenase, superoxide dismutase, vitamins $\mathrm{C}$ and $\mathrm{E}$, beta-carotene, uric acid [11]. However, when the presence of ROS and RNS overcomes the physiologic antioxidant defences, an oxidative stress status, occurs. Thus, as an adjunct to optimal antibiotic therapy, antioxidant/anti-inflammatory therapy is warranted to avoid a decline in lung function and tissue damage.

\subsection{Respiratory drug delivery}

Inhalation drug therapy consists of drug administration directly to the lung in form of micronized droplets or solid microparticles, highly recommended especially in pathologies affecting the lung (i.e. asthma, cystic fibrosis, chronic obstructive pulmonary disease). The administration of the active compound directly in the airways can be of great advantage: after inhalation, the site where the drug is deposited is less aggressive in terms of $\mathrm{pH}$ and enzymatic attach; additionally, the hepatic first-passage effect is bypassed. Both aspects influence the dose administered, which can be decreased compared to oral route. Moreover, the permeability of pulmonary epithelium is higher than the intestinal mucosa, due to a reduced resistance to substance transport. Finally, the drug dissolution, critical for many compounds, is less relevant in the case of solids, since the active compound is a very fine powder that impacts with a high surface area. In addition to biopharmaceutical aspects, inhalation bioavailability requires the deposition of the dose in the lung i.e., the active compound must be formulated in a respirable form. Development of formulations for inhalation is particularly challenging since the preparation of a respirable formulation and the selection of an adequate device for the administration are both required. Formulation and device constitute the dosage forms and affect the bioavailability of the inhaled drug. Concerning the formulation, dry powder inhalers (DPI) are preferred to solutions/suspensions due to drug stability, high concentration at the site of action and lack of propellant. The biggest issue encountered when formulating a dry powder for inhalation is its size which has to be small enough to guarantee the aerosolization and the deposition at the appropriate site of the respiratory tract. A failure in deposition may result in a failure of efficacy. Given that any discussion about the right size of particles for inhalation is meaningless without the consideration of their geometry and density, the concept of aerodynamic diameter has been introduced. The aerodynamic diameter (Dae) is a spherical equivalent diameter and derives from the equivalence between the inhaled particle and a sphere of unit density $\left(\rho_{0}\right]$ undergoing sedimentation at the same rate (Eq. 1). 


$$
\operatorname{Dae}=\operatorname{Dv} \sqrt{\frac{\rho}{\chi \rho_{0}}}
$$

where Dv is the volume-equivalent diameter, $\rho$ is the particle density and $\chi$ is the shape factor.

Hence, the aerodynamic behaviour depends on particle geometry, density and volume diameter: a small spherical particle with a high density will behave aerodynamically as a bigger particle, being poorly transported in the lower airways. The Dae can be improved reducing the volume diameter and the density or increasing the shape factor of the particles, by means of different processes, i.e. dry or wet milling, spray-drying, spray-freeze drying, and supercritical fluid technology. Among these, spray drying is a commonly used technique for the preparation of dry powders for inhalation.

\subsection{Spray drying}

Spray drying is a one-step process able to convert liquid feeds (i.e., solutions, suspensions and emulsions) in a dry powder. Firstly, the liquid is broken into droplets by means of a nozzle atomizer (atomization step); then, droplets come in contact with a heated gas in the drying chamber and the drying step starts; finally, the dried particles are separated from the heated gas by means of a cyclone (separation step) and collected into a glass container. The optimization of the aerodynamic properties of the powders produced via spray drying can be achieved modulating process parameters, solvent composition, solute concentration, liquid feed rate, inlet temperature, gas pressure and aspiration.

\subsection{The challenge of excipients for dry powder inhalers}

The primary function of the lung is respiration. To fulfil this purpose, the lung has a large surface area and a thin membranes. Many compounds have been tested to overcome drug delivery outcomes related to the small particle size requested for deposition. For example, in the spray drying process the powder properties can be modulated adding excipients able to affect the evaporation of spray droplets during the drying and consequently the particle shape. The safety of an inhalation drug product has to be taken into account: the structural and functional integrity of respiratory epithelium must be respected. This hardly limits the choice of excipients available for the formulation to few compounds, like sugars (lactose, mannitol and glucose) and hydrophobic additive (magnesium stearate, DSPC). As a matter of fact, natural amino acids (AAs) possess good safety profiles and, recently, showed to enhance flow aid properties when co-spray-dried with active compounds. As a support to AAs pulmonary safety, a formulation of Aztreonam and lysine (Cayston ${ }^{\circledR}$, powder for instant solution and inhalation) has been recently approved by FDA for CF patients.

\section{Aerosolized antioxidant and anti-inflammatory agents in Cystic Fibrosis}

Oxidative stress has been identified as an early complication in the airways of infants and young children affected by CF $[12,13]$. Recent clinical data suggest that oxidative damage of 
pulmonary proteins during chronic infection may contribute to the decline of lung function in CF patients [14]. The massive infiltration of neutrophils in lungs of CF patients leads to the generation of oxygen-derived reactive oxygen species (ROS) and, in particular, $\mathrm{H}_{2} \mathrm{O}_{2}$ that contributes to irreversible lung damage and, ultimately, to patient death. Activated neutrophils migrate to the airways and release large amounts of ROS. On the other hand in CF epithelial cells, antioxidant defense systems appear to be defective in their ability to control the amount of ROS produced [15]. Therefore over-abundance of ROS and their products may cause tissue injury-events and modify intracellular signalling pathways leading to cell apoptosis and enhanced inflammatory processes. In addition to its $\mathrm{Cl}^{-}$ channel function, CFTR has been proposed to carry antioxidant-reduced glutathione. A recent study demonstrated that oxidative stress can suppress CFTR expression and function while increasing the cellular GSH content. Chronic lung inflammation with episodes of acute exacerbations initiates several physiological and metabolic changes with harmful effects including weight loss and metabolic breakdown. Antioxidants (glutathione, vitamins, beta-carotene, selenium and flavonoids) as dietary support or pharmacological treatment can be a promising approach. Great attention has been focused on flavonoids [16, 17], polyphenolic compounds with antioxidant, anti-inflammatory and antibacteric activity, hugely present in fruits and vegetables. Among natural flavonoids, naringin (N, Fig. 1) extracted from grapefruits has shown anti-inflammatory, antioxidant and anticarcinogenic effects [18].

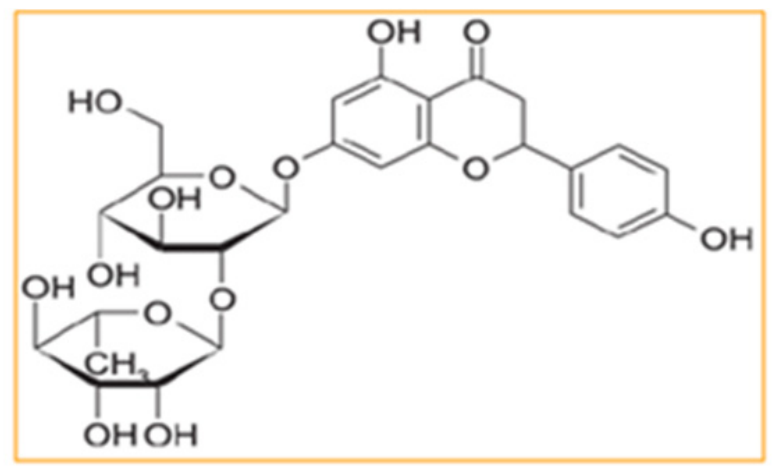

Figure 1. Naringin 4,5,7-trihydroxyflavanone 7-rhamnoglucosyde

In addition, recent studies have reported that flavonoids may act as CFTR direct activators, stimulating transepithelial chloride transport [19-21]. Although flavonoids are inhibitors of tyrosine kinases and phosphatases, their effects on CFTR are probably independent of these activities, resulting from direct binding to an NBD of phosphorylated CFTR [22].

With the aim to discover more effective activators of G551D-CFTR [19], some investigators have begun to examine the relationship between the chemical structure of flavonoids and their effects on CFTR $\mathrm{Cl}_{i}$ i channels. This study served to identify the pharmacophore portion of the skeletons molecular basis for interaction with the NBD. The well-documented antioxidant effect of flavonoids is unfortunately more evident in vitro than in vivo, due to the 
high concentration needed, the susceptibility to oxidation and instability to the gastric $\mathrm{pH}$ in which they undergo hydrolysis and enzymatic degradation. Moreover, flavonoids show a very slight solubility in water, which leads to a very low dissolution rate, an irregular absorption of the drug from oral solid dosage forms in the gastrointestinal tract and a limited bioavailability. Despite a number of publications focused on the antioxidant effect of flavonoids, rather no attention has been addressed yet to their formulation in order to increase bioavailability. Recently, oral hydrophilic swellable matrices for a controlled release of some flavonoids $[23,24]$ and gastroresistant microparticles aiming at overcoming the acid environment have been formulated [25, 26]. An alternative strategy may be the direct aerosol delivery to the lung, which has the advantage to achieve higher locally available concentration of the antioxidant in the airways.

\subsection{Naringin dry powders production and characterization}

Naringin is a very slightly soluble molecule: its lipophilia can affect the dissolution of the drug when in contact with the liquids lining the lung. The micronization by means of spray drying process and addition of opportune additives able to improve powder wettability seem to be a valid strategy for the formulation of an efficacious dry powder inhaler. Micronized particles were produced by completely dissolving the active naringin $(\mathrm{N})$ alone (\#NET3) or with $5 \% \mathrm{w} / \mathrm{w}$ of leucine (\#NET3-leu5) as dispersibility enhancer in $7 / 3$ water/ethanol solutions $[27,28]$. Spray drying conditions were: inlet temperature $110^{\circ} \mathrm{C}$, drying air flow $500 \mathrm{~L} / \mathrm{min}$, aspirator $100 \%$, feed rate $5 \mathrm{ml} / \mathrm{min}$, nozzle $0.5 \mathrm{~mm}$. Aerodynamic properties were determined by means of both single stage glass impinger (SSGI) and Andersen cascade impactor (ACI). The device used for the DPI deposition tests was the Turbospin (kindly donated by PH\&T SpA) in which the dose to be aerosolized was premetered in a size 2 gelatine capsule. Results demonstrated that the presence of leucine in the feed solution influenced particle size distribution, as well as powder density and morphology. Firstly, NET3-leu5 showed a $d_{50}$ sensibly lower than NET3, evidencing a positive effect of leucine on particle diameter.

\begin{tabular}{|c|c|c|c|c|}
\hline Code \# & $\begin{array}{c}\text { Leu content } \\
(\% \mathrm{w} / \mathrm{w})\end{array}$ & Spray yield $(\%)$ & $\begin{array}{c}\mathrm{d} 50(\mu \mathrm{m}) \text { and } \\
\text { span }\end{array}$ & FPF $(\%)$ \\
\hline NET3 & 0 & $59.4 \pm 0.3$ & $5.2[1.6]$ & $44.5 \pm 1.5$ \\
\hline NET3-leu5 & 5 & $60.7 \pm 2.5$ & $3.3[1.7]$ & $51.3 \pm 1.6$ \\
\hline
\end{tabular}

FPF, fine particle fraction

Table 1. Composition, spray drying yield, particle size distribution and fine particle fraction after SSGI of Naringin powders.

Moreover, as showed by thermograms of NET3-leu5, DSC analyses indicated that spraydried powders containing the AA were amorphous materials. Spray drying process caused the loss of crystalline habitus of both $\mathrm{N}$ and leu raw material as evidenced by the absence of 
the endotherms corresponding to $\mathrm{N}$ crystal melting point $\left(247^{\circ} \mathrm{C}\right.$, Fig. $\left.2 \mathrm{~b}\right)$ and leu crystal melting point $\left(275^{\circ} \mathrm{C}\right.$, Fig. 2a).

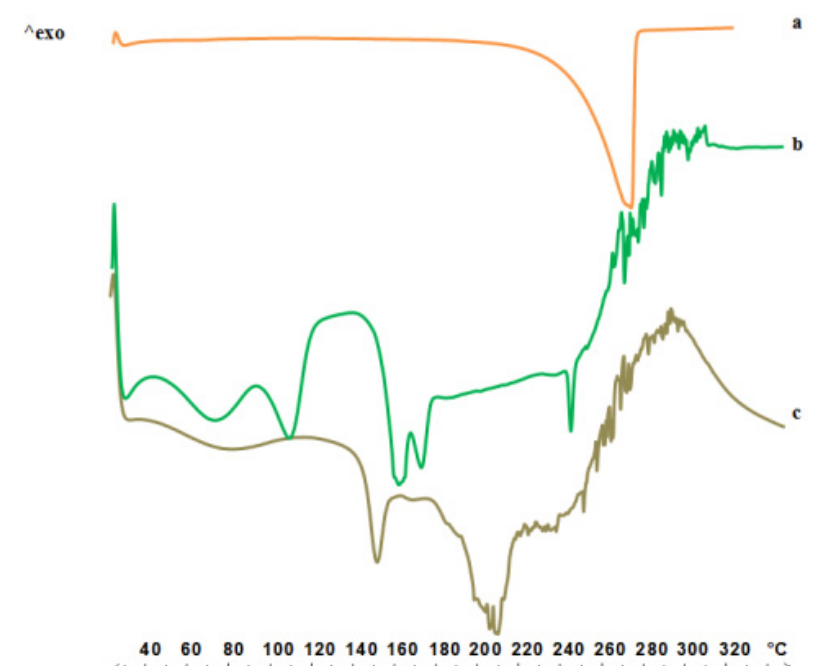

Figure 2. Differential scanning calorimetry thermograms of Naringin raw material (a), Leucine raw material (b) and NET3-leu5 (c).

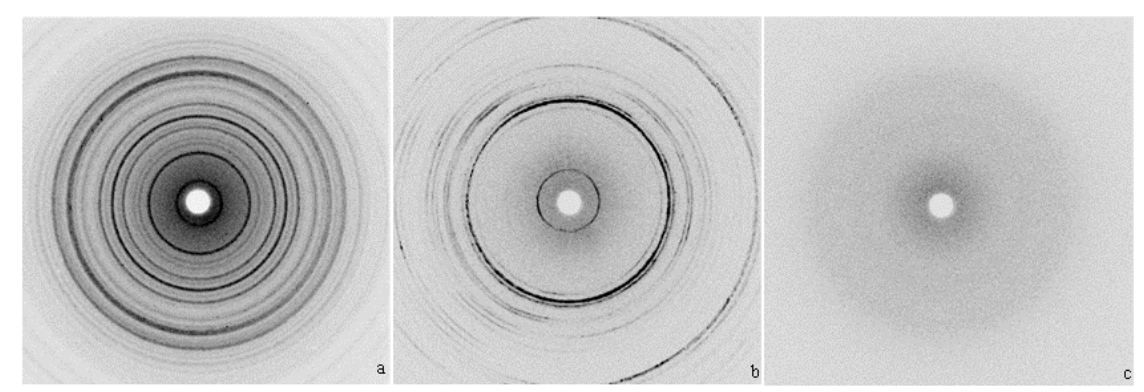

Figure 3. X-ray patterns of Naringin raw material (a), Leucine raw material (b) and NET3-leu5(c).

DSC results were confirmed by X-ray assessments, showing no crystalline state in NET3leu5 powder. In figure $3 \mathrm{X}$-ray patterns of $\mathrm{N}$ (Fig. 3a) and leu (Fig. 3b) as raw materials were reported in comparison with X-ray patterns of NET3-leu5 (Fig. 3c). The loss in crystallinity is an important issue for drugs, such as $\mathrm{N}$, very slightly soluble in water, bringing to an increase of solid solubility.

Microscopy observation revealed that particle morphology was affected by leucine content in the liquid feed: samples containing only $\mathrm{N}$ appeared as small particles, spherical in shape or very slightly corrugated and their SEM micrographs showed widespread aggregation (Fig. 4a). 
On the contrary, micrographs of samples produced with 5\% leu displayed well separated particles with corrugated, raisin-like surfaces (Fig. 4b), beneficial for particles intended for inhalation.

In fact, previous reports suggested that improvement of the respirable fraction may be obtained not only by lowering the size or the density of a powder, but also reducing interparticulate cohesion $[29,30]$. Corrugated particles might also be more appropriate for dissolution in the lung fluid due to a larger area.

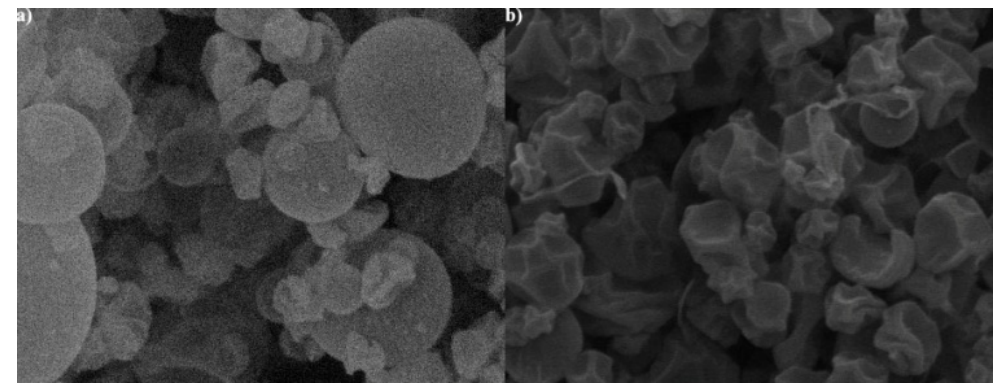

Figure 4. SEM picture of (a) NET3 and NET3-leu5

Regarding the in vitro deposition test by means of SSGI, the AA affected the aerodynamic properties of spray-dried powders as reported in table 1. NET3-leu5 showed an improvement of FPF due to both a reduction in the capsule and device retention and an increase in powder dispersibility. The latter is likely to be related to the absence of aggregates and high degree of particle corrugation, as observed by SEM analyses. These data were confirmed by ACI experiments (Fig. 5).

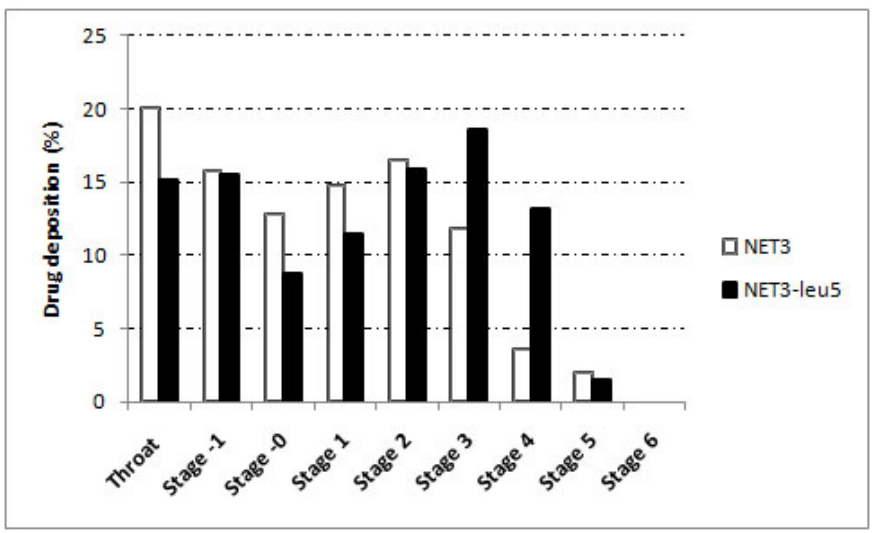

Figure 5. ACI deposition patterns of NET3 (white bars) and NET3-leu5 (black bars).

The powder containing the dispersibility agent (NET3-leu5) showed a lower deposition in the throat compared to NET3, with a resulting higher quantity of drug recovered from the deeper stages and an improving of the fine particle fraction. 
These results are in agreement with previous report on the ability of surface corrugation to decrease interparticulate cohesion by reducing Van der Waals forces between particles and, consequently, increase powder respirability.

In conclusion, the use of leucine as excipient was useful to reduce adhesion between particles and improve powder dispersion, when delivered from dry powder inhalers. Therefore, a careful formulation plays a key role in the aerosol performance of $\mathrm{N}$ dry powders: NET3-leu5 showed optimezed bulk and aerodynamic behaviour.

Moreover, the spray drying process, reducing particle size while improving particle superficial area exposed to fluids, caused a greater (up to 30 fold higher, Fig. 6) immediate solubility of micronized powders (NET3 and NET3-leu5] when in contact with water at $37^{\circ} \mathrm{C}$, compared to unprocessed commercial batch (rawN). Leucine addition to powder formulation (NET3-leu5) further increased $\mathrm{N}$ solubility which started declining very quikly, reaching a nearly constant value after 30 minutes, due to recrystallization of the amorphous material.

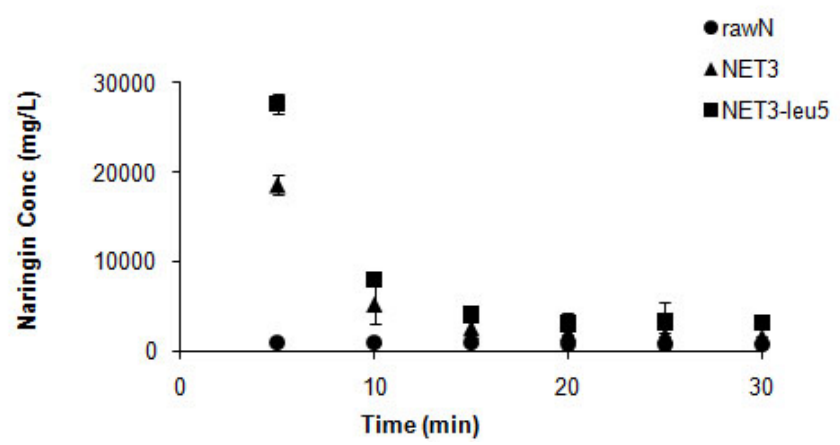

Figure 6. Aqueous solubility at $37^{\circ} \mathrm{C}$ of rawN (commercial batch, circles), NET3 (spray-dried batch without excipient, triangles) and NET3-leu5 (spray-dried batch with $5 \%$ leu, squares).

\subsection{In vitro biological activities of $\mathbf{N}$ dry powders in bronchial epithelial cells}

The developed dry powders have to be tested for verifying the ability to control airways inflammation. Two immortalized cell lines were selected as in vitro models: one, called CuFi1 (CF cells), was derived from human airway epithelial (HAE) cells of CFTR $\Delta \mathrm{F} 508 / \Delta \mathrm{F} 508$ mutant genotype, the other, called NuLi1 (normal lung), was derived from a non-CF subject and used as control. These cell lines exhibited transepithelial resistance, maintained the ion channel physiology expected for the genotypes and retained NF- $\kappa \mathrm{B}$ responses to inflammatory stimuli $[31,32]$ Cytotoxicity and effects on NF- $\kappa B$ pathway and on IL-6 and IL-8 release were examined.

\subsubsection{Effect of $N$ and its formulations on cell viability}

Cytotoxicity (MTT assay) and cell viability (BrUd) evaluations (from 15 to $150 \mu \mathrm{m}$ ) showed that neither rawN nor NET3 and NET3-leu5 are cytotoxic or cytostatic in both CF and non- 
CF bronchial cells. After a $24 \mathrm{~h}$ treatment, rawN did not significantly affect cell viability, as determined by MTT assay in the concentration ranging from 15 to $150 \mu \mathrm{M}$ (data not shown), but it caused a dose-dependent reduction of cell growth of different extent in NuLi1 and CuFi1 cells, from 60 to $150 \mu \mathrm{M}$ (Fig. 7a). Interestingly, spray-dried powders containing leucine induced a dose-dependent and significant cell growth inhibition only in normal bronchial NuLi1 cells (Fig. 7c), while it determined a 14\% increase of cell proliferation in CuFi1 cells at the highest dose $(150 \mu \mathrm{M})$. To evaluate the contribution of the AA to the increased cell proliferation induced by NET3-leu5 in CuFi1, Leu spray-dried alone was also tested. The AA did not show any significant effect in NuLi1 cells while it was able to increase CuFi1 cell proliferation at all the concentrations tested (Fig. 7d).
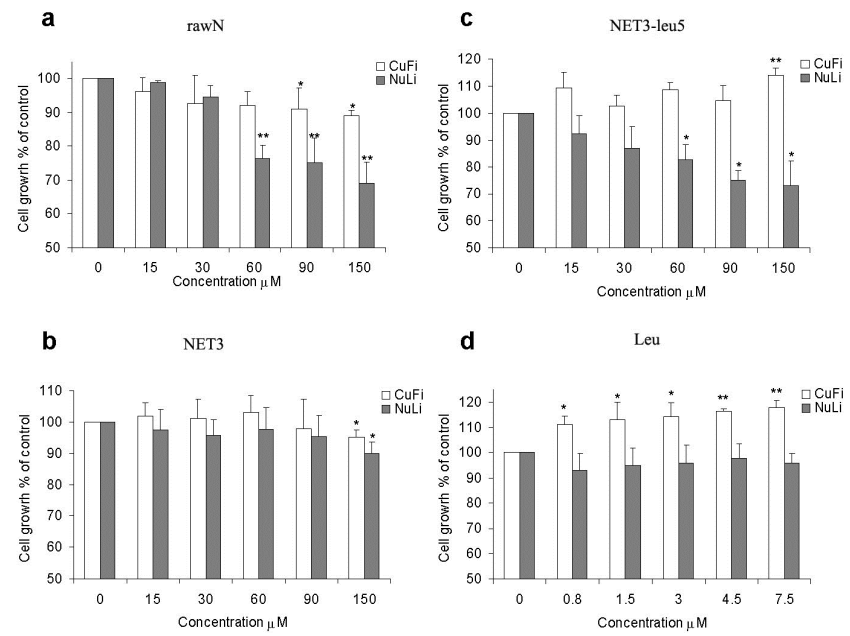

Figure 7. Naringin and its DPI formulations do not inhibit CuFi1 and NuLi1 cell proliferation at concentrations lower than $60 \mu \mathrm{M}$. Cells were treated for $24 \mathrm{~h}$ with: (a) raw Naringin (rawN), (b) spraydried Naringin (NET3), (c) N co-sprayed with $5 \%$ leucine (NET3-leu5) (from 0.8 to $7.5 \mu \mathrm{M}$ ). Cell growth was determined using a colorimetric bromodeoxyuridine (BrdU) cell proliferation ELISA kit. The histograms report the percentage of growing cells in comparison with untreated cells (control, $100 \%$ proliferation). All data are shown as mean \pm SD of three independent experiments each done in duplicate $\left({ }^{*} \mathrm{P}<0.05\right.$ and ${ }^{* *} \mathrm{P}<0.01$ vs control).

This finding suggests that the technological improvement of immediate drug solubility and powder flowability, as well as the presence of the AA, may increase the drug uptake and improve the CF cell altered metabolism, reducing the toxicity observed for unprocessed rawN (Fig. 7a). In accordance, increased and altered basal protein catabolism has been reported in CF patients by many reports [33-35].

\subsubsection{Effect of $N$ and its formulations on $N F-\kappa B$ pathway}

To study the anti-inflammatory effects of $\mathrm{N}$ in CuFi1 cells, we investigated the main molecular targets of NF- $\mathrm{\kappa B}$ pathway in CuFi1 in comparison to normal bronchial NuLi1 
cells. The NF- $\mathrm{KB}$ pathway is well known to play a crucial role in inflammatory process (36). In resting cells, the transcription factor NF- $\mathrm{KB}$ exists as homo- or heterodimer, maintained inactive in the cytosol by a family of inhibitor proteins named $\operatorname{I\kappa Bs}(\operatorname{I\kappa B} \alpha, \beta, \varepsilon)$. In response to a wide range of stimuli such as cytokines and bacterial or viral products, IкB proteins are phosphorylated by IкB kinases (IKK $\alpha$ and $\beta$ ), ubiquitinated and degraded by the $26 \mathrm{~S}$ proteasome. As a consequence, $\mathrm{NF}-\kappa \mathrm{B}$ dimers can localize into the nucleus and positively regulate the transcription of proinflammatory genes (37). This pathway is overactivated also in absence of any infection (38-40) in CF cells. In our experiments, CuFi1 cells exhibit higher expression levels of IKK $\beta$ and phosphoIKB $\alpha$ proteins compared to their normal counterpart NuLi1 cells (data from Western Blot analysis not shown). The effects of rawN, NET3 and NET3-leu5 at sub-toxic concentrations $(30 \mu \mathrm{M})$ were evaluated at 2,6 and $24 \mathrm{~h}$ on IKK $\beta$ and $\mathrm{I} \kappa \mathrm{B} \alpha$ kinases, measuring both the expression levels and the phosphorylation status of the main molecular targets of the NF- $\mathrm{KB}$ pathway (i.e. IKK $\alpha$, IKK $\beta$ and $\operatorname{I\kappa B} \alpha$ ). Results are reported in figure 8 .

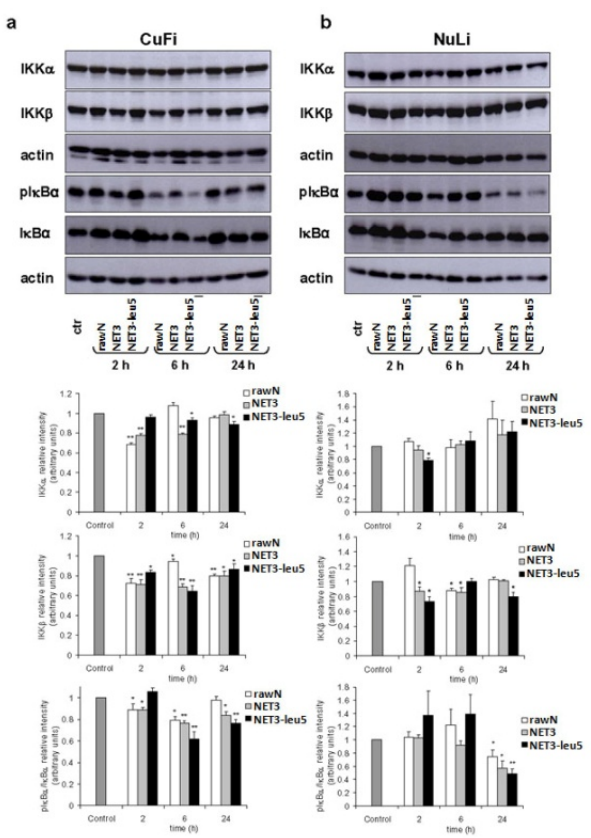

Figure 8. Naringin and its DPI formulations inhibit the key enzymes of the NF- $\mathrm{KB}$ pathway in CF bronchial epithelial cells. CuFi1 (a) and NuLi1 (b) cells were treated with raw Naringin (rawN), spraydried Naringin (NET3) and N co-sprayed with 5\% leucine (NET3-leu 5) at $30 \mu \mathrm{M}$ concentration for the indicated time points. Cell lysates were analyzed by Western blot with antibodies against IKK $\alpha$, IKK $\beta$ and $\mathrm{pI \kappa B} \alpha$. Same filters were stripped and re-probed with total IкB $\alpha$ and anti-actin used as loading control. More representative results are shown (upper panels). Immunoreactive bands were quantified using Quantity One program. Densitometric analyses (mean \pm SD) of three independent experiments are reported as relative intensity of IKK $\alpha$, IKK $\beta$ or $\mathrm{pI \kappa B} \alpha / \mathrm{I} \kappa \mathrm{B} \alpha$ on actin and expressed as arbitrary units vs control (lower panels). ( ${ }^{*} \mathrm{P}<0.05$ and ${ }^{* *} \mathrm{P}<0.01$ vs control). 
As regards to IKK $\alpha$, NET3 and NET3-leu5 caused a reduction of IKK $\alpha$ but rawN did not in CuFi1 cells, while all powders did not cause any significant effect in normal airways epithelial cells (Fig. 8b). As IKK $\beta$, its expression was generally reduced in CuFi1 cells: the highest decrease was observed at $6 \mathrm{~h}$ in NET3-leu5-treated cells (Fig. 8b). Interestingly, the observed reduction of expression levels of both the enzymatic subunits of the IKK complex in $\mathrm{CuFi}$ led to a significant and prolonged decrease of $\operatorname{I\kappa B} \alpha$ phoshorylation. In fact, this effect started early $(2 \mathrm{~h})$ and was retained all over the treatment time $(24 \mathrm{~h})$ in CF bronchial epithelial cells (Fig. 8a). On the contrary, in normal bronchial epithelial cells only a delayed $(24 \mathrm{~h})$ decrease of IкB $\alpha$ phosphorylation was observed as a consequence of the reduction of IKK $\beta$ subunit only expression level. Leucine spray-dried alone did not give any significant result in all Western Blot analyses (data not shown).

Previous evidence indicates that IKK $\beta$ plays a more crucial role for NF- $\kappa B$ activation in response to pro-inflammatory cytokines and microbial products [40], even though both the catalytic subunits of the IKK complex are able to regulate NF- $\mathrm{KB}$ activation and have a complementary role in the control of inflammation [41]. $\mathrm{N}$ formulations are effective in inhibiting both IKK subunits expression, and therefore caused a prolonged reduction of $\mathrm{I} \kappa \mathrm{B} \alpha$ phosphorylation in CuFi1 cells.

\subsubsection{Effect of $N$ and its formulation on Interleukin-8 (IL-8) and interleukin-6 (IL-6) release}

The direct effect of NET3-leu5 on the main cytokines involved in inflammatory response, interleukin 8 (IL-8) and interleukin 6 (IL-6) was also investigated. To this aim, CuFi1 cells were treated with NET3-Leu5 at 30 and $60 \mu \mathrm{M}$ in the presence and absence of LPSstimulation from Pseudomonas aeruginosa. Results (Fig. 9) showed that NET3-leu5 inhibited both cytokine production in unstimulated as well as in LPS-stimulated CuFi1 cells and the production of IL-8 more than IL-6.
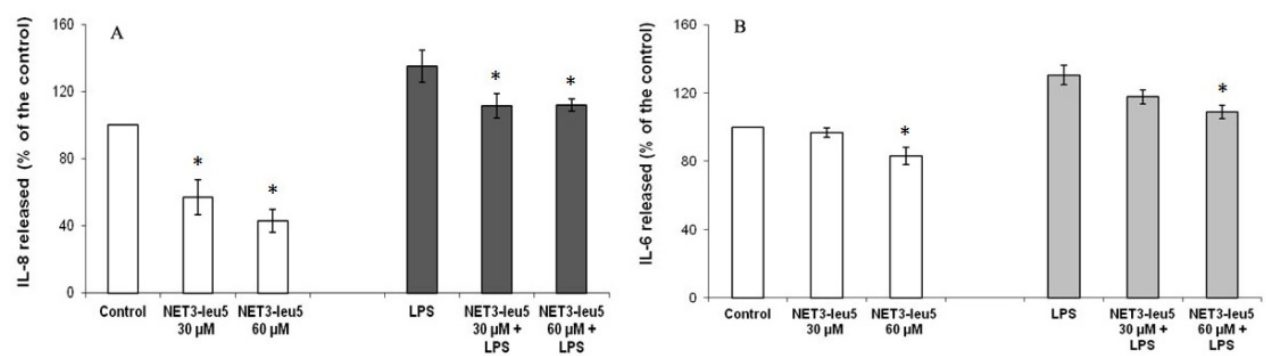

Figure 9. Effect of Naringin co-sprayed with $5 \%$ leucine (NET3-leu5) on basal and LPS-induced secretion of IL-8 (A) and IL-6 (B) in Cystic Fibrosis bronchial epithelial (CuFi1) cells. Data are presented as mean percentage of released cytokines in the control supernatants (untreated and unstimulated) $\pm \mathrm{SD}$ of two independent experiments each done in duplicate. ( ${ }^{*} \mathrm{P}<0.05 \mathrm{vs}$ control supernatants).

These data indicate that the inhibition of NFkB pathway by NET3-leu5 results in a reduction of the release of pro-inflammatory cytokines. NET3-leu5 seems involved in controlling the 
pro-inflammatory status of CF cells in the presence as well as in the absence of bacterial stimulation. However, LPS-stimulated cytokine secretion is dependent on Toll-like receptor4 (TLR-4] signaling which expression is reduced in the CF airway epithelial cells, promoting the bacterial colonization and chronic infection in CF lung (42).

\section{Aerosolized antibiotics in cystic fibrosis}

Pulmonary infections are the major cause of morbidity and mortality in cystic fibrosis (CF), with Pseudomonas aeruginosa $(\mathrm{Pa})$ acting as the princISOl pathogen. The viscous mucus lining the lung of CF patients impairs the mucociliary function, facilitating recurrent and chronic respiratory infections caused mainly by $\mathrm{Pa}$ but also by Haemophilus influenzae, Bulkolderia cepacia $[7,8]$. Treatment of lung disease by antibiotics is an accepted standard in CF cure aiming at reducing decline in lung function and number of hospitalizations [43]. Aminoglycosides, such as gentamicin sulfate (G) (Fig. 10), are indicated in the management of acute exacerbations of CF as well as in the control of chronic infection and eradication of $\mathrm{Pa}$ infections. Various clinical studies on gentamicin inhalation treatment in cystic fibrosis patients chronically infected with Pseudomonas aeruginosa have shown that antibiotic solutions for aerosol treatment produce both subjective and objective improvement. Interestingly, among aminoglycosides, $G$ has shown the ability to partially restore the expression of the functional protein CFTR (cystic fibrosis transmembrane conductance regulator) in CF mouse models bearing class I nonsense mutations [44-47]. In particular, Du and coll. [45] demonstrated that $G$ was able to induce the expression of a higher CFTR level compared to tobramycin. Aminoglycoside antibiotics can suppress premature termination codons by allowing an amino acid to be incorporated in place of the stop codon, thus permitting translation to continue to the normal end of the transcript. Regarding the use of aminoglycosides in the treatment of airways infections and class I CFTR mutations, the main problem is their reduced penetration in the endobronchial space after intravenous (IV) administration, combined with their high systemic toxicity. Since aminoglycosides peak sputum concentrations are only 12 to $20 \%$ of the peak serum concentrations [48] to achieve adequate drug concentrations at the site of action, it is necessary to use large IV doses, which may produce serum levels associated with renal and oto-toxicity.

These problems can be overcome by the use of aerosolized aminoglycosides, which can deliver high dose of drug directly to the lungs, while minimizing systemic exposure. Therefore, the first aim of the research was to develop micronized gentamicin powders, easy to handle and stable for long time; the second goal was to obtain a dry powder suitable for pulmonary administration.

\subsection{Design and development of a new dry powder inhaler of gentamicin}

Differently from Naringin, Gentamicin is a very soluble drug: as its high hydrophilia guarantees a rapid drug solubility and diffusion in the fluids lining the lung, as it may cause high hygroscopicity and instability, preventing the formulation of a stable and respirable dry powder. As it is well known, hygroscopicity modulates the moisture content of the 


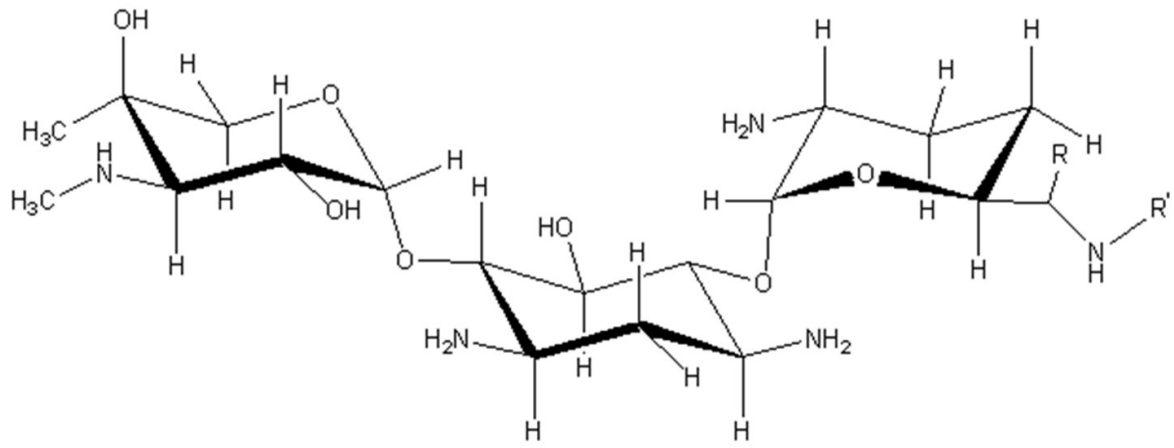

$\mathrm{H}_{2} \mathrm{SO}_{4}$

\begin{tabular}{|l|l|l|}
\hline & R & R' $^{\prime}$ \\
\hline Gent.C1 & $\mathrm{CH}_{3}$ & $\mathrm{CH}_{3}$ \\
\hline Gent.C2 & $\mathrm{CH}_{3}$ & $\mathrm{H}$ \\
\hline Gent.C1a & $\mathrm{H}$ & $\mathrm{H}$ \\
\hline
\end{tabular}

Figure 10. Gentamicin sulfate structure.

particles in the final dosage form prior to aerosol generation and it is correlated to chemical or physical instability of the product. For aerosols formulation, the agglomeration leads to an inability to generate particles of respirable size. Moreover, as aerosol particles enter the lungs, they experience a high-humidity environment $\left(99.5 \%\right.$ relative humidity at $\left.37^{\circ} \mathrm{C}\right)$ : inhaled particles may be subject to hygroscopic growth, increasing their dimensions and affecting lung deposition. In this case, excipients able to modify the hygroscopic properties of a drug need to be considered. A dry powder formulation was obtained by co-spraydrying Gentamicin and leucine from $7 / 3$ hydro-alcoholic solutions, using an organic solvent less polar than ethanol, the isopropanol. Microparticles were designed while studying the effect of leu, feed composition and process parameters on particle formation, physicochemical properties and aerosol performance. In addition, the effect of the engineered particles on cell viability and cell proliferation of CuFi1 cells was investigated.

\subsubsection{Manufacturing and characterization of G/leu co-spray-dried powders}

Due to its high polarity, G raw material was deliquescent, becoming liquid after 1 hour of exposure to room conditions. In order to reduce hygroscopicity and to increase powder dispersibility, G was subject to spray drying process alone or with leu as flowability enhancer using water or water-isopropanol (ISO) mixtures.

Preliminarly, the solubilities of the drug and excipient in the feed systems were determined; $\mathrm{G}$ freely soluble in water exhibited the lowest solubility in water/ISO 7/3 (v/v) system, the poor solubility of leu is even lower in water-co-solvent systems (Table 2). 


\begin{tabular}{ccc}
\hline Liquid feed composition & $\mathrm{G}(\mathrm{mg} / \mathrm{ml})$ & Leu $(\mathrm{mg} / \mathrm{ml})$ \\
\hline Water & Freely soluble & $24.2 \pm 1.0$ \\
Water/ISO 8/2 (v/v) & $351.8 \pm 25.1$ & $11.2 \pm 0.5$ \\
Water/ISO 7/3 (v/v) & $135.9 \pm 24.6$ & $9.5 \pm 0.2$ \\
\hline
\end{tabular}

Table 2. Gentamicin and L-leucine solubility in liquid feeds used for spray drying at $\mathrm{pH} 7.0 \pm 0.1$.

As reported in Table 3, addition of the organic co-solvent into the water feed was extremely helpful in terms of process yield suggesting a reduction in powder cohesiveness and, therefore, a potential enhancement of the aerosolisation properties (49). Differently, leu addition did not have a linear effect on spray drying yield (Table 3).

\begin{tabular}{|c|c|c|c|c|}
\hline & Code \# & Leu content $(\% \mathrm{w} / \mathrm{w})$ & Process yield (\%) & $\mathrm{d}_{50}(\mu \mathrm{m})$ and span \\
\hline \multirow{5}{*}{ 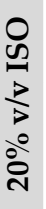 } & GISO2 & 0 & $78.0 \pm 3.8$ & $4.74[2.10]$ \\
\hline & GISO2-leu5 & 5 & $73.9 \pm 0.5$ & $6.19[1.88]$ \\
\hline & GISO2-leu10 & 10 & $65.0 \pm 5.5$ & $4.07[1.81]$ \\
\hline & GISO2-leu15 & 15 & $84.6 \pm 3.3$ & $3.72[1.58]$ \\
\hline & GISO2-leu5 & 20 & $77.5 \pm 0.6$ & $4.82[1.73]$ \\
\hline \multirow{5}{*}{ 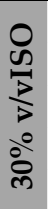 } & GISO3 & 0 & $85.5 \pm 0.7$ & 4.24 [1.97] \\
\hline & GISO3-leu5 & 5 & $86.6 \pm 1.2$ & $3.77[1.36]$ \\
\hline & GISO3-leu10 & 10 & $85.9 \pm 0.9$ & $3.69[1.51]$ \\
\hline & GISO3-leu15 & 15 & $82.0 \pm 2.1$ & $3.90[1.62]$ \\
\hline & GISO3-leu20 & 20 & $80.8 \pm 1.3$ & $4.11[1.90]$ \\
\hline
\end{tabular}

Table 3. Physical characteristics of spray dried particles: liquid fees composition, process yield, particle size and bulk density.

Optimized process parameters led to micronized powders with $\mathrm{d}_{50}$ (ranging from $3.7 \mu \mathrm{m}$ to $4.8 \mu \mathrm{m}$ ) similar for all batches produced (Table 3), with no evident effect of solvent and leu content on the particles diameter.

Organic co-solvent had a massive effect on hygroscopicity too (Fig. 11). In particular, by adding $30 \% \mathrm{v} / \mathrm{v}$ of ISO into the aqueous feed, humidity uptake by $\mathrm{G}$ powders was reduced from $10.5 \%$ (water) to $4.8 \%$ (water/ISO) after exposure at room conditions. In the presence of $10 \% \mathrm{w} / \mathrm{w}$ leu, G lost its water avidity [0.9\% weight gained after $80 \mathrm{~min}$ ). These effects may be explained by the addition of the lower-soluble component (leu) into the liquid feeds, able to reach the critical concentration for shell formation as the droplet evaporation progresses during spray-drying process [50]. Such enrichment in leu at the particle surface seems to slow down water uptake of hygroscopic drug such as $G$, in agreement with previous observations [51] and, potentially, increase powder flowability.

Leu effect on spray-dried powders appears clearly, after microscopy studies, as an evident increase in particle corrugation. Morphology studies showed an increase in particle 
corrugation as an effect of leu presence in spray-dried powders. As an example, SEM pictures of particles dried from 8:2 water/ISO ratio solutions were reported in figure 12 .

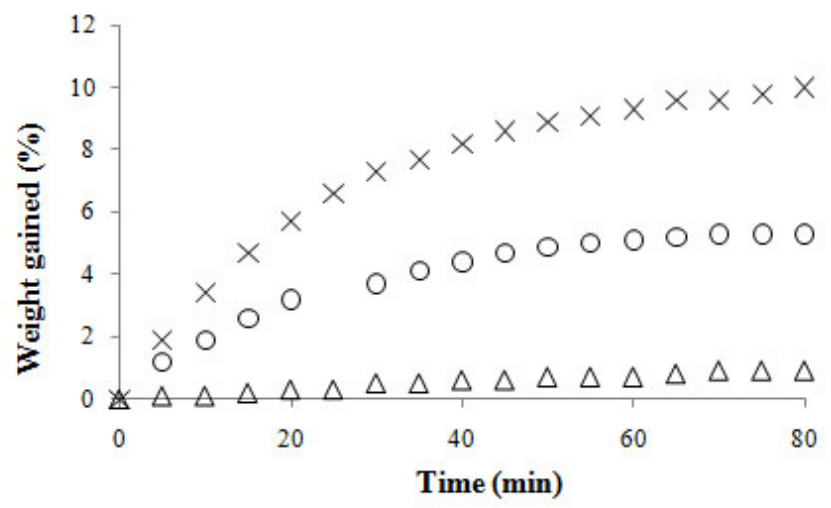

Figure 11. Weight gained after $80 \mathrm{~min}$ of exposure at room conditions by $\mathrm{G}$ raw material (cross), $\mathrm{G}$ spray-dried from 7:3 w water-ISO (circles) v/v systems, and G/10\%leu spray-dried from water-ISO 7:3 $\mathrm{v} / \mathrm{v}$ mixture (triangles).

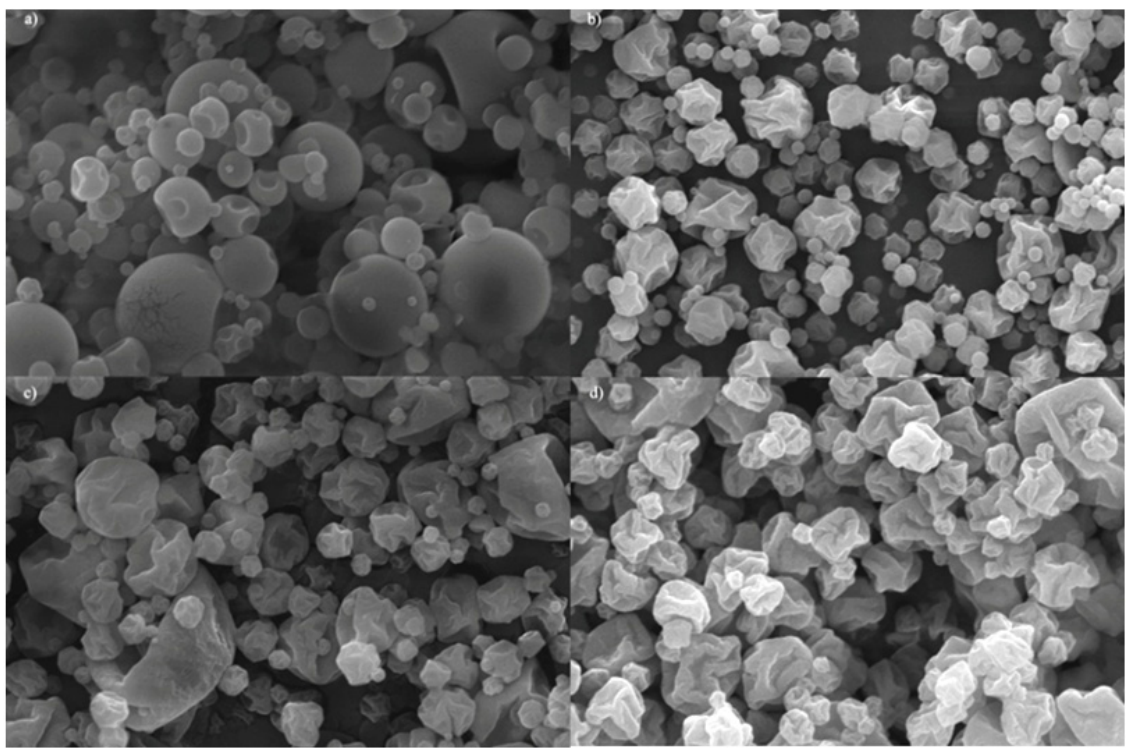

Figure 12. SEM pictures of powders dried from water/ISO 8:2 v/v systems containing: a) G; b) GISO2leu5; c) GISO2-leu10; d) GISO2-leu5. 
As well known, the morphology of spray-dried particles is strongly influenced by the solubility of the components and their initial saturation in the liquid feeds. G, freely soluble in water, led to the formation of spherical particles when spray dried alone (Fig. 12a, G). According to previous observations [52], during the co-spray drying process, the saturation of the lower-soluble component (leu) may increase faster than that of hydrophilic one $(\mathrm{G})$, due to the preferential evaporation of alcohol and the associated change in the solvent/co-solvent ratio. This led to the formation of a primary solid shell which collapsed, hence corrugated microparticles were formed. As the relative amount of the less soluble component increased, particle corrugation was more and more evident; particles from almost spherical became raisins like (Fig. 12b, GISO2leu5) or irregularly wrinkled (Fig.12d, GISO2-leu5). Such surface modification has been shown to be beneficial for particles intended for inhalation [29]: a corrugated surface improves powder dispersibility by minimizing contact areas and reducing interparticulate cohesion and, therefore, corrugated particles disperse better than spherical ones.

\subsubsection{Aerodynamic behavior of G/leu powders}

As aerodynamic properties, batches dried from water were hygroscopic, cohesive powders, difficult to insert into and come out from the capsule and with unsatisfying aerodynamic properties (data not shown). In particular, neat $G$ dried from water was a cohesive and sticky material, unable to be aerosolized.

\begin{tabular}{|c|c|c|c|c|c|c|}
\hline & Code \# & $\begin{array}{c}\text { Leu content } \\
(\% \mathrm{w} / \mathrm{w})\end{array}$ & $\begin{array}{c}\text { Charged } \\
\text { Dose (mg) }\end{array}$ & ED (\%) & FPF (\%) & $\mathrm{FPD}(\mathrm{mg})$ \\
\hline \multirow{5}{*}{ 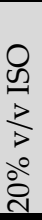 } & GISO2 & 0 & 60 & $95.8 \pm 1.9$ & $14.5 \pm 7.8$ & $8.7 \pm 4.7$ \\
\hline & GISO2-leu5 & 5 & 80 & $98.0 \pm 0.2$ & $21.9 \pm 5.1$ & $16.6 \pm 3.9$ \\
\hline & GISO2-leu10 & 10 & 120 & $99.4 \pm 0.1$ & $32.6 \pm 5.6$ & $35.2 \pm 6.0$ \\
\hline & GISO2-leu15 & 15 & 120 & $99.6 \pm 0.2$ & $46.8 \pm 0.5$ & $47.7 \pm 0.5$ \\
\hline & GISO2-leu5 & 20 & 120 & $99.3 \pm 0.3$ & $50.9 \pm 1.0$ & $48.8 \pm 0.9$ \\
\hline \multirow{5}{*}{ 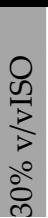 } & GISO3 & 0 & 60 & $90.9 \pm 7.9$ & $13.4 \pm 8.5$ & $7.5 \pm 4.9$ \\
\hline & GISO3-leu5 & 5 & 70 & $97.2 \pm 0.5$ & $22.3 \pm 3.0$ & $14.8 \pm 2.0$ \\
\hline & GISO3-leu10 & 10 & 110 & $99.4 \pm 1.1$ & $28.8 \pm 5.0$ & $28.4 \pm 5.0$ \\
\hline & GISO3-leu15 & 15 & 120 & $99.1 \pm 0.3$ & $49.4 \pm 0.8$ & $50.4 \pm 0.8$ \\
\hline & GISO3-leu20 & 20 & 120 & $99.2 \pm 0.0$ & $50.2 \pm 1.0$ & $48.2 \pm 0.9$ \\
\hline
\end{tabular}

ED, emitted dose; FPF, fine particle fraction; FPD, fine particle dose

Table 4. Aerodynamic properties of spray-dried powders after single stage glass impinger deposition experiments; device TURBOSPIN, charged with capsules type 2 (mean \pm SD of three experiments).

G spray drying from hydroalcoholic solvent (GISO2 and GISO3) reduced powder cohesivity and enabled the aerosolization process; however, the resulting aerodynamic properties were still not satisfying (FPF less than 15\%; Table 4). The inclusion of leu substantially increased emitted doses (ED up to $99.6 \%$ for \#GISO2-leu15) and fine particle fractions (FPF up to $49.4 \%$ for \#GISO3-leu15). Taking into account the relative reduction in drug content, further increase in the excipient/drug ratio up to 20/80 w/w did not improve DPI performance. The organic co-solvent led to the best 
FPF and FPD values. As example, GISO3-leu15 formulations, containing 15\% w/w of leu and obtained from $30 \% \mathrm{v} / \mathrm{v}$ of ISO/water feed, emitted $50.4 \mathrm{mg}$ of fine $\mathrm{G}$ after one actuation of the Turbospin device. These results are in agreement with previous studies [29, 30, 53] evidencing the enhancement of powder aerosol performance as particle surface corrugation goes up to a certain degree; further corrugation enhancement did not improve aerodynamic properties. The plot in figure 13 allows to appreciate a dramatic increase in both particle corrugation (SEM micrographs) and FPF as the leu content increased.

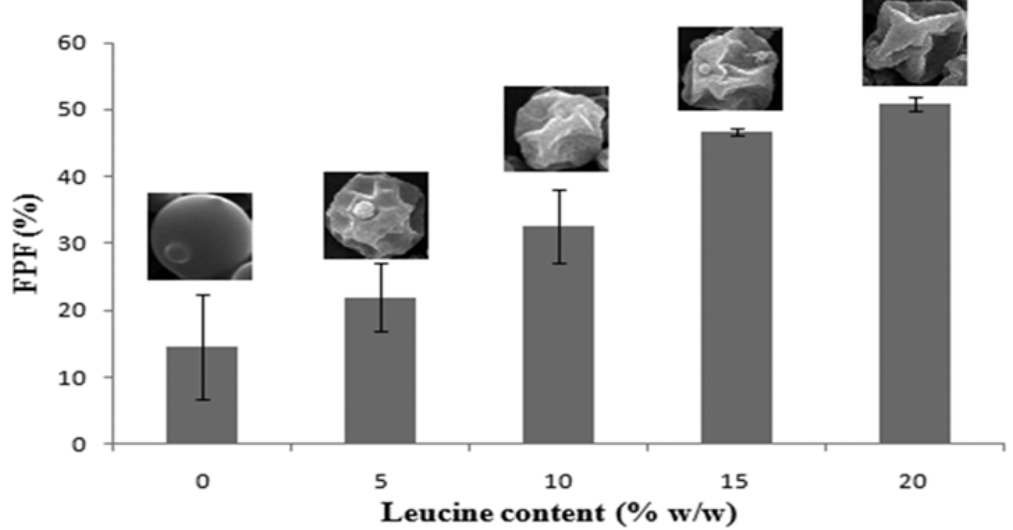

Figure 13. FPF and SEM images of G powders spray-dried from liquid feeds containing $20 \%$ ISO and increasing amount of leu.

MMAD, FPF and FPD values obtained by Andersen cascade impactor deposition studies (Table 5) confirmed the observed trend. Capsules charged with $120 \mathrm{mg}$ of powder emitted almost the whole dose from the device after the pump actuation, as indicated by ED $\geq 99 \%$. Among all formulations, GISO3-leu15 (G/15\%leu from 30\% v/v of ISO/water feed) showed very satisfying aerodynamic properties as proved by MMAD of $3.45 \mu \mathrm{m}, \mathrm{FPF} 58.1 \%$ and FPD of $56.4 \mathrm{mg}$ (Table 5).

\begin{tabular}{|c|c|c|c|c|c|}
\hline & Code \# & ED (\%) & MMAD $(\mu \mathrm{m})$ & $\begin{array}{l}\text { FPD } \\
(\mathrm{mg})\end{array}$ & FPF (\%) \\
\hline \multirow{2}{*}{ 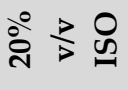 } & GISO2-leu15 & $99.7 \pm 0.3$ & $4.0 \pm 0.1$ & $49.3 \pm 1.7$ & $46.0 \pm 2.7$ \\
\hline & GISO2-leu5 & $99.6 \pm 0.4$ & $4.2 \pm 0.1$ & $39.3 \pm 0.3$ & $42.5 \pm 0.2$ \\
\hline \multirow{2}{*}{ 官 } & GISO3-leu15 & $99.2 \pm 0.3$ & $3.4 \pm 0.2$ & $56.4 \pm 1.1$ & $58.1 \pm 3.6$ \\
\hline & GISO3-leu20 & $99.2 \pm 0.2$ & $3.3 \pm 0.1$ & $54.7 \pm 2.2$ & $58.0 \pm 0.5$ \\
\hline
\end{tabular}

Table 5. Aerodynamic properties of G spray-dried powders containing 15 or $20 \% \mathrm{w} / \mathrm{w}$ leu after Andersen cascade impactor deposition experiments (mean \pm SD)

\subsubsection{Effect of $G /$ leu powders on viability of cf airways epithelium}

In order to establish whether the particle engineering has any cytotoxic or cytostatic effect on bronchial epithelial cells [31, 32], CuFi1 cells were treated for $24 \mathrm{~h}$ with increasing 
concentrations (from 0.0002 to $2 \mu \mathrm{M}$ expressed as G content) of GISO3 or GISO-Leu15 powders in comparison to raw $G$. Results indicated that neither raw $G$ nor its formulations generally inhibited cells viability as determined by MTT assay (Fig. 14 B). Only Raw G at concentrations higher than $0.02 \mu \mathrm{M}$ showed a slight but significant decrease in cell survival. An interesting observation is that an increase in leu content up to $15 \%$, as in GISO3-leu15, faintly but not significantly decreased CuFi1 viability at concentration ranging from 0.02 to $0.2 \mu \mathrm{M}(\mathrm{P}<0.05)$ (Fig. $13 \mathrm{~B}$ ) whereas at $2.0 \mu \mathrm{M}$ did not. As previously oserved in formulations for inhalation containing leucine [27], this effect seems to be related to leu ability to improve cell proliferation and metabolism of bronchial epithelial CF cells.

Furthermore ELISA BrdU immunoassay confirmed that raw $\mathrm{G}$ slightly reduced CF cell growth only at the highest concentration $[2 \mu \mathrm{M}, \mathrm{P}<0.01]$ (Fig. $14 \mathrm{~A}$ ).

Therefore, G/leu systems had no cytotoxic or cytostatic effect on CF epithelial lung cells (CuFi1 model), at concentrations up to $2 \mu \mathrm{M}$.
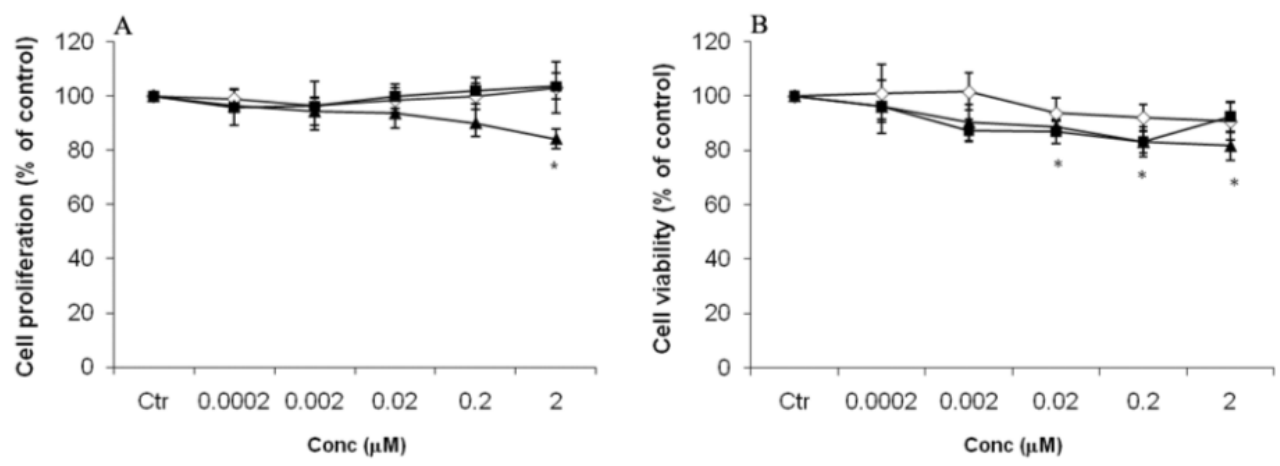

Figure 14. Effect of Gentamicin and its DPI formulations on CuFi1 cell proliferation and viability. Cells were treated for $24 \mathrm{~h}$ with: raw Gentamicin (rawG, $\mathbf{\Lambda}$ ), spray-dried Gentamicin (GISO3 $\diamond$ ) and $\mathrm{G}$ cosprayed with $15 \% \mathrm{w} / \mathrm{w}$ leucine (GISO3-leu15 a) at concentrations from $0.0002 \mu \mathrm{M}$ to $2 \mu \mathrm{M}$. Cell growth (A) was determined using a colorimetric bromodeoxyuridine (BrdU) cell proliferation ELISA kit. Cell viability (B) was determined by MTT assay. All data are shown as mean \pm SD of three independent experiments, each done in duplicate $\left({ }^{*} P<0.05\right.$ and ${ }^{* *} P<0.01$ vs control).

An proper engineering process, use of hydro-alcoholic feeds and the AA addition, allow the preparation of micronized powders able to be aerosolized. The addition of small amount of the AA led to the production of dry formulations with excellent emitted dose and good aerodynamic properties after actuation of the Turbospin device. Finally, the engineered particles showed no cytotoxic or cytostatic effect on bronchial epithelial cells bearing a CFTR F508/F508 mutant genotype.

\section{Conclusions}

The engineering process by spray drying and the use of water-co-solvent systems as liquid feed allowed micronized powders to be produced with high yield, starting from Naringin or Gentamicin sulfate, drugs with different physicochemical properties. The addition of a small 
amount of a safe excipient, as leucine, led to powders with excellent emission doses, counteracting both $\mathrm{G}$ high hygroscopicity and $\mathrm{N}$ cohesiveness and low solubility. In particular, N DPI containing 5\% leu (NET3-leu5) and G DPI containing 15\% leu (GISO3leu15 ) were able to deliver almost the total dose of drug loaded in the capsules, with about $60 \%$ of FPF. Finally, N and G engineered powders showed no cytotoxic or cytostatic effect on bronchial epithelial cells bearing a CFTR F508/F508 mutant genotype. As to efficacy, NET3-leu5 powder, containing natural polyphenol and AA, were able to negatively modulate NF-kB pathways in absence of stimulation in bronchial epithelia and to reduce the overexpressed IL-8 and IL-6 production both in basically and in LPS-stimulated conditions. These findings, together with the well-known $G$ antibiotic activity support the use of G-leu and N-leu DPIs in the treatment of infections and intrinsic inflammation of CF lungs.

\section{Author details}

Paola Russo, Antonietta Santoro, Lucia Prota, Mariateresa Stigliani and Rita P. Aquino* Department of Pharmaceutical and Biomedical Sciences, University of Salerno, Fisciano, Italy

\section{References}

[1] Cheng SH, Gregory RJ, Marshall J, Paul S, Souza DW, White GA, et al. Defective intracellular transport and processing of CFTR is the molecular basis of most cystic fibrosis. Cell. 1990;63(4):827-34. Epub 1990/11/16.

[2] Collins FS, Riordan JR, Tsui LC. The cystic fibrosis gene: isolation and significance. Hosp Pract (Off Ed). 1990;25(10):47-57. Epub 1990/10/15.

[3] Schwiebert EM, Egan ME, Hwang TH, Fulmer SB, Allen SS, Cutting GR, et al. CFTR regulates outwardly rectifying chloride channels through an autocrine mechanism involving ATP. Cell. 1995;81(7):1063-73. Epub 1995/06/30.

[4] Vankeerberghen A, Cuppens H, Cassiman JJ. The cystic fibrosis transmembrane conductance regulator: an intriguing protein with pleiotropic functions. J Cyst Fibros. 2002;1(1):13-29. Epub 2004/10/07.

[5] Mehta A. CFTR: more than just a chloride channel. Pediatr Pulmonol. 2005;39(4):292-8. Epub 2004/12/02.

[6] Quinton PM. Cystic fibrosis: impaired bicarbonate secretion and mucoviscidosis. Lancet. 2008;372(9636):415-7. Epub 2008/08/05.

[7] Mukhopadhyay S, Singh M, Cater JI, Ogston S, Franklin M, Olver RE. Nebulised antipseudomonal antibiotic therapy in cystic fibrosis: a meta-analysis of benefits and risks. Thorax. 1996;51(4):364-8. Epub 1996/04/01.

[8] Ramsey BW, Pepe MS, Quan JM, Otto KL, Montgomery AB, Williams-Warren J, et al. Intermittent administration of inhaled tobramycin in patients with cystic fibrosis. Cystic Fibrosis Inhaled Tobramycin Study Group. N Engl J Med. 1999;340(1):23-30. Epub 1999/01/08.

\footnotetext{
${ }^{*}$ Corresponding Author
} 
[9] Doring G, Hoiby N. Early intervention and prevention of lung disease in cystic fibrosis: a European consensus. J Cyst Fibros. 2004;3(2):67-91. Epub 2004/10/07.

[10] Konstan MW, Hilliard KA, Norvell TM, Berger M. Bronchoalveolar lavage findings in cystic fibrosis patients with stable, clinically mild lung disease suggest ongoing infection and inflammation. Am J Respir Crit Care Med. 1994;150(2):448-54. Epub 1994/08/01.

[11] Rahman I, Biswas SK, Kode A. Oxidant and antioxidant balance in the airways and airway diseases. Eur J Pharmacol. 2006;533(1-3):222-39. Epub 2006/02/28.

[12] Brown RK, McBurney A, Lunec J, Kelly FJ. Oxidative damage to DNA in patients with cystic fibrosis. Free Radic Biol Med. 1995;18(4):801-6. Epub 1995/04/01.

[13] Cantin AM, White TB, Cross CE, Forman HJ, Sokol RJ, Borowitz D. Antioxidants in cystic fibrosis. Conclusions from the CF antioxidant workshop, Bethesda, Maryland, November 11-12, 2003. Free Radic Biol Med. 2007;42(1):15-31. Epub 2006/12/13.

[14] Starosta V, Griese M. Oxidative damage to surfactant protein D in pulmonary diseases. Free Radic Res. 2006;40(4):419-25. Epub 2006/03/07.

[15] Boncoeur E, Criq VS, Bonvin E, Roque T, Henrion-Caude A, Gruenert DC, et al. Oxidative stress induces extracellular signal-regulated kinase $1 / 2$ mitogen-activated protein kinase in cystic fibrosis lung epithelial cells: Potential mechanism for excessive IL-8 expression. Int J Biochem Cell Biol. 2008;40(3):432-46. Epub 2007/10/16.

[16] Kumar P, Khanna M, Srivastava V, Tyagi YK, Raj HG, Ravi K. Effect of quercetin supplementation on lung antioxidants after experimental influenza virus infection. Exp Lung Res. 2005;31(5):449-59. Epub 2005/07/16.

[17] Kumar P, Sharma S, Khanna M, Raj HG. Effect of Quercetin on lipid peroxidation and changes in lung morphology in experimental influenza virus infection. Int J Exp Pathol. 2003;84(3):127-33. Epub 2003/09/17.

[18] Limasset B, le Doucen C, Dore JC, Ojasoo T, Damon M, Crastes de Paulet A. Effects of flavonoids on the release of reactive oxygen species by stimulated human neutrophils. Multivariate analysis of structure-activity relationships (SAR). Biochem Pharmacol. 1993;46(7):1257-71. Epub 1993/10/05.

[19] Springsteel MF, Galietta LJ, Ma T, By K, Berger GO, Yang H, et al. Benzoflavone activators of the cystic fibrosis transmembrane conductance regulator: towards a pharmacophore model for the nucleotide-binding domain. Bioorg Med Chem. 2003;11(18):4113-20. Epub 2003/08/21.

[20] Pyle LC, Fulton JC, Sloane PA, Backer K, Mazur M, Prasain J, et al. Activation of the cystic fibrosis transmembrane conductance regulator by the flavonoid quercetin: potential use as a biomarker of DeltaF508 cystic fibrosis transmembrane conductance regulator rescue. Am J Respir Cell Mol Biol. 2010;43(5):607-16. Epub 2010/01/01.

[21] Virgin F, Zhang S, Schuster D, Azbell C, Fortenberry J, Sorscher EJ, et al. The bioflavonoid compound, sinupret, stimulates transepithelial chloride transport in vitro and in vivo. Laryngoscope. 2010;120(5):1051-6. Epub 2010/04/28.

[22] Kunzelmann K, Schreiber R, Boucherot A. Mechanisms of the inhibition of epithelial $\mathrm{Na}(+)$ channels by CFTR and purinergic stimulation. Kidney Int. 2001;60(2):455-61. Epub 2001/07/28.

[23] Lauro MR, Torre ML, Maggi L, De Simone F, Conte U, Aquino RP. Fast- and slowrelease tablets for oral administration of flavonoids: rutin and quercetin. Drug Dev Ind Pharm. 2002;28(4):371-9. Epub 2002/06/12. 
[24] Lauro MR, Torre ML, De Simone F, Conte U, Aquino RP. Tablet formulation for the fast and sustained-release of flavonoids: naringin and naringenin. STP Pharma Sciences. 2001;11:265-9.

[25] Lauro MR, De Simone F, Sansone F, Iannelli P, Aquino RP. Preparations and release characteristics of Naringin and Naringenin gastro-resistant microparticles by spraydrying. J Drug Del Sci Tech. 2007;17:119-24.

[26] Lauro MR, Maggi L, Conte U, De Simone F, Aquino RP. Rutin and Quercetin gastroresistant microparticles obtained by spray-drying technique. J Drug Del Sci Tech. 2005;15:363-9.

[27] Prota L, Santoro A, Bifulco M, Aquino RP, Mencherini T, Russo P. Leucine enhances aerosol performance of naringin dry powder and its activity on cystic fibrosis airway epithelial cells. International journal of pharmaceutics. 2011;412(1-2):8-19. Epub 2011/04/05.

[28] Sansone F, Aquino RP, Del Gaudio P, Colombo P, Russo P. Physical characteristics and aerosol performance of naringin dry powders for pulmonary delivery prepared by spray-drying. European journal of pharmaceutics and biopharmaceutics : official journal of Arbeitsgemeinschaft fur Pharmazeutische Verfahrenstechnik eV. 2009;72(1):206-13. Epub 2008/11/11.

[29] Chew NY, Chan HK. Use of solid corrugated particles to enhance powder aerosol performance. Pharm Res. 2001;18(11):1570-7. Epub 2002/01/05.

[30] Chew NY, Tang P, Chan HK, Raper JA. How much particle surface corrugation is sufficient to improve aerosol performance of powders? Pharm Res. 2005;22(1):148-52. Epub 2005/03/18.

[31] Dechecchi MC, Nicolis E, Norez C, Bezzerri V, Borgatti M, Mancini I, et al. Antiinflammatory effect of miglustat in bronchial epithelial cells. J Cyst Fibros. 2008;7(6):555-65. Epub 2008/09/26.

[32] Zabner J, Karp P, Seiler M, Phillips SL, Mitchell CJ, Saavedra M, et al. Development of cystic fibrosis and noncystic fibrosis airway cell lines. Am J Physiol Lung Cell Mol Physiol. 2003;284(5):L844-54. Epub 2003/04/05.

[33] Holt TL, Ward LC, Francis PJ, Isles A, Cooksley WG, Shepherd RW. Whole body protein turnover in malnourished cystic fibrosis patients and its relationship to pulmonary disease. Am J Clin Nutr. 1985;41(5):1061-6. Epub 1985/05/01.

[34] Levy LD, Durie PR, Pencharz PB, Corey ML. Effects of long-term nutritional rehabilitation on body composition and clinical status in malnourished children and adolescents with cystic fibrosis. J Pediatr. 1985;107(2):225-30. Epub 1985/08/01.

[35] Switzer M, Rice J, Rice M, Hardin DS. Insulin-like growth factor-I levels predict weight, height and protein catabolism in children and adolescents with cystic fibrosis. J Pediatr Endocrinol Metab. 2009;22(5):417-24. Epub 2009/07/22.

[36] Yamamoto Y, Gaynor RB. Role of the NF-kappaB pathway in the pathogenesis of human disease states. Curr Mol Med. 2001;1(3):287-96. Epub 2002/03/20.

[37] Hayden MS, Ghosh S. Signaling to NF-kappaB. Genes Dev. 2004;18(18):2195-224. Epub 2004/09/17.

[38] Lyczak JB, Cannon CL, Pier GB. Lung infections associated with cystic fibrosis. Clin Microbiol Rev. 2002;15(2):194-222. Epub 2002/04/05. 
[39] Rottner M, Kunzelmann C, Mergey M, Freyssinet JM, Martinez MC. Exaggerated apoptosis and NF-kappaB activation in pancreatic and tracheal cystic fibrosis cells. FASEB J. 2007;21(11):2939-48. Epub 2007/04/20.

[40] Verhaeghe C, Remouchamps C, Hennuy B, Vanderplasschen A, Chariot A, Tabruyn SP, et al. Role of IKK and ERK pathways in intrinsic inflammation of cystic fibrosis airways. Biochem Pharmacol. 2007;73(12):1982-94. Epub 2007/05/01.

[41] Descargues P, Sil AK, Karin M. IKKalpha, a critical regulator of epidermal differentiation and a suppressor of skin cancer. EMBO J. 2008;27(20):2639-47. Epub 2008/09/27.

[42] John G, Yildirim AO, Rubin BK, Gruenert DC, Henke MO. TLR-4-mediated innate immunity is reduced in cystic fibrosis airway cells. Am J Respir Cell Mol Biol. 2010;42(4):424-31. Epub 2009/06/09.

[43] Prayle A, Smyth AR. Aminoglycoside use in cystic fibrosis: therapeutic strategies and toxicity. Curr Opin Pulm Med. 2010;16(6):604-10. Epub 2010/09/04.

[44] Clancy JP, Bebok Z, Ruiz F, King C, Jones J, Walker L, et al. Evidence that systemic gentamicin suppresses premature stop mutations in patients with cystic fibrosis. Am J Respir Crit Care Med. 2001;163(7):1683-92. Epub 2001/06/13.

[45] Du M, Jones JR, Lanier J, Keeling KM, Lindsey JR, Tousson A, et al. Aminoglycoside suppression of a premature stop mutation in a Cftr-/- mouse carrying a human CFTRG542X transgene. J Mol Med (Berl). 2002;80(9):595-604. Epub 2002/09/13.

[46] Wilschanski M, Yahav Y, Yaacov Y, Blau H, Bentur L, Rivlin J, et al. Gentamicininduced correction of CFTR function in patients with cystic fibrosis and CFTR stop mutations. N Engl J Med. 2003;349(15):1433-41. Epub 2003/10/10.

[47] Wilschanski M, Famini C, Blau H, Rivlin J, Augarten A, Avital A, et al. A pilot study of the effect of gentamicin on nasal potential difference measurements in cystic fibrosis patients carrying stop mutations. Am J Respir Crit Care Med. 2000;161(3 Pt 1):860-5. Epub 2000/03/11.

[48] Mendelman PM, Smith AL, Levy J, Weber A, Ramsey B, Davis RL. Aminoglycoside penetration, inactivation, and efficacy in cystic fibrosis sputum. Am Rev Respir Dis. 1985;132(4):761-5. Epub 1985/10/01.

[49] Li HY, Seville PC, Williamson IJ, Birchall JC. The use of amino acids to enhance the aerosolisation of spray-dried powders for pulmonary gene therapy. J Gene Med. 2005;7(3):343-53. Epub 2004/10/30.

[50] Vehring R. Pharmaceutical particle engineering via spray drying. Pharm Res. 2008;25(5):999-1022. Epub 2007/11/28.

[51] Shur J, Nevell TG, Ewen RJ, Price R, Smith A, Barbu E, et al. Cospray-dried unfractionated heparin with L-leucine as a dry powder inhaler mucolytic for cystic fibrosis therapy. J Pharm Sci. 2008;97(11):4857-68. Epub 2008/03/21.

[52] Lechuga-Ballesteros D, Charan C, Stults CL, Stevenson CL, Miller DP, Vehring R, et al. Trileucine improves aerosol performance and stability of spray-dried powders for inhalation. J Pharm Sci. 2008;97(1):287-302. Epub 2007/09/08.

[53] Weiler C, Egen M, Trunk M, Langguth P. Force control and powder dispersibility of spray dried particles for inhalation. J Pharm Sci.99(1):303-16. Epub 2009/06/18. 